\title{
Longitudinal and cross sectional analyses of exposure to coal mine dust and pulmonary function in new
} miners

\author{
Noah S Seixas, Thomas G Robins, Michael D Attfield, Lawrence H Moulton
}

\begin{abstract}
The association between exposure to dust and pulmonary function was studied by longitudinal and cross sectional analyses in a group of United States underground coal miners beginning work in or after 1970. Quantitative estimates of exposure to respirable coal mine dust were derived from air samples taken periodically over the entire study period. The cohort included 977 miners examined both in round 2 (R2) (1972-5) and round 4 (R4) (1985-8) of the National Study of Coal Workers' Pneumoconiosis. Multiple linear regression models were developed for both cross sectional (pulmonary function at $R 2$ and $R 4$ ) and longitudinal (change in pulmonary function botween $R 2$ and R4) analyses with exposure partitioned into pre-R2 and post-R2 periods and controlled for covariates including smoking history. The results indicate a rapid initial (at R2) loss of FVC and $\mathrm{FEV}_{1}$ in association with cumulative exposure of the order of $30 \mathrm{ml}$ per $\mathrm{mg} / \mathrm{m}^{3}$-years. Between $\mathrm{R2}$ and $\mathrm{R4}$ (about 13 years) no additional loss of function related to dust exposure was detected although the percentage of predicted FVC and FEV $_{1}$ did decline over the period. After some 15 years since first exposure (at R4), a statistically
\end{abstract}

Department of Environmental Health, SC-34, University of Washington, Seattle, WA98195, USA N S Seixas

Department of Environmental and Industrial Health, University of Michigan, School of Public Health, Ann Arbor, MI 48109-2029, USA

T G Robins

Division of Respiratory Disease Studies, National Institute for Occupational Safety and Health, Morgantown, WV 26505, USA

M D Attfield

Department of Biostatistics, University of Michigan, School of Public Health, Ann Arbor, MI, 48109-2029; current address:

Department of International Health, The John Hopkins University, School of Hygiene and Public Health, 615 N Wolfe St, Baltimore, MD 21205, USA L H Moulton significant association of cumulative exposure with $F E V_{1}$ of about $-5.9 \mathrm{ml}$ per $\mathrm{mg} / \mathrm{m}^{3}$-years was found. These results indicate a significant non-linear effect of exposure to dust on pulmonary function at dust concentrations present after regulations took effect. The initial responses in both the FVC and FEV ${ }_{1}$ are consistent with inflammation of the small airways in response to exposure to dust.

\section{(British fournal of Industrial Medicine 1993;50:929-937)}

Cross sectional analyses of respiratory disease in coal miners have provided strong evidence for an exposure-response relation between cumulative exposure to dust and decrements in pulmonary function ${ }^{1-6}$ and increased prevalence of symptoms of chronic bronchitis. ${ }^{78}$ None the less, longitudinal studies may provide a more sensitive design for the detection of low level effects and for examination of temporal aspects of the exposure-disease relation.

Two among several longitudinal analyses of pulmonary function in coal miners are of particular interest. Love and Miller ${ }^{9}$ studied the change in forced expiratory volume in one second $\left(\mathrm{FEV}_{1}\right)$ between two surveys about 11 years apart in 1677 long term (average age 45) British coal miners. Results of this analysis showed a loss of around $0.6 \mathrm{ml}$ per $\mathrm{mg} / \mathrm{m}^{3}$-year exposure before the first survey. A relation between cumulative exposure between the two surveys and change in $\left(\mathrm{FEV}_{1}\right)$ was also found but only if the effect of coal mine was left out of the models. Attfield ${ }^{10}$ completed a comparable study in 1072 United States miners over nine years. Exposure estimates relied on years worked for the period before the study (average nine years) and on personal dust measurements between the two surveys. Results of this analysis indicated a weak association $(p=0 \cdot 12)$ of average dust concentrations with decrements in $\mathrm{FEV}_{1}$ and a statistically significant $(p<0.05)$ decline of $7.3 \mathrm{ml}$ in $\mathrm{FEV}_{1}$ for each year worked at the face between the surveys. Although these studies generally confirm a relation between exposure to coal dust and a fall in $\mathrm{FEV}_{1}$, their design limits the interpretation of 
the reported outcomes. The United States study used relatively unstable quantitative estimates only for the concurrent exposure period and used years underground as a surrogate for earlier exposures. Neither of these studies considered the relation of dust exposure to loss of forced vital capacity (FVC). Most importantly, both studies included only miners with long histories of mining work, limiting their ability to examine the effects of initial exposure on respiratory health.

This study considers the effect of exposures to coal dust on pulmonary function through both longitudinal and cross sectional analyses. The subjects included participants in round 4 (R4) (1985-8) of the National Study of Coal Workers' Pneumoconiosis (NSCWP) who started work during or after 1970, the year in which national exposure standards came into effect in the United States. The initial exposure limit was set at $3.0 \mathrm{mg} / \mathrm{m}^{3}$ of respirable dust on 31 December 1969 and this was lowered to $2.0 \mathrm{mg} / \mathrm{m}^{3}$ three years later. ${ }^{11}$ The same miners had also been studied in round 2 (R2) (1972-5) of the NSCWP; thus each participant had been given at least two pulmonary function tests 11 to 18 years apart. Also, quantitative estimates of exposure were available for the cohort based on federal government sampling data over the entire study period. Thus with these quantitative historical exposure data and two sets of pulmonary function studies, the current study considers the exposure-response relations with time in a group of new miners.

\section{Methods}

The cohort for this analysis was similar to one previously described. ${ }^{12} 13$ That cohort was defined by the criteria: (1) they were men; (2) they were surveyed by the NSCWP at R4, (3) their first mining job was reported in their R4 work history in 1970 or later and their R2 work history did not suggest more than one year of pre-1970 mining work; (4) they had at least three pulmonary function test manoeuvres meeting the American Thoracic Society (ATS) acceptability requirements ${ }^{14}$ at R4. For this analysis, the only other requirement was that the miner had also completed acceptable pulmonary function tests at R2. Hence, each participant had begun work as a coal miner from one to five years before testing at R2 and 15 to 18 years before testing at $\mathbf{R 4}$.

The methods of data collection used at $\mathrm{R} 2$ were similar to those used at R4 and included a chest radiograph, a British Medical Research Council respiratory symptom questionnaire, work history, and pulmonary function tests. Spirometry was conducted according to the ATS guidelines in effect at the time by technicians trained by a highly qualified
National Institute of Occupational Safety and Health pulmonary physiologist. The testing equipment used was the same (dry rolling seal volume displacement spirometers) in both $\mathrm{R} 2$ and $\mathrm{R} 4$. The FVC and $\mathrm{FEV}_{1}$ were obtained from the largest value found regardless of the exhalation from which it derived. Two procedures used in $\mathrm{R} 2$ were different from those adopted at R4. Firstly, a maximum of five manoeuvres were elicited in R2 to obtain three acceptable values whereas up to 10 were obtained in R4. This is unlikely to lead to any substantial bias as most subjects will obtain three acceptable values within five attempts. ${ }^{15}$ Secondly, timed volumes, for example, $\mathrm{FEV}_{1}$, were originally obtained by the flow threshold method at R2 and according to the 1979 ATS recommendations ${ }^{14}$ by back extrapolation at R4. To ensure comparability with R2 results for this analysis, R4 results were recalculated from flow threshold methods. Consistent with the ATS guidelines, no reproducibility criteria were applied to the cohort. Results from an analysis of the effect of reproducibility on the $\mathbf{R} 4$ results were presented in a previous paper. ${ }^{13}$

Variables of pulmonary function considered in this analysis were the FVC, $\mathrm{FEV}_{1}$, and their ratio $\mathrm{FEV}_{1} / \mathrm{FVC}$. Cross sectional analyses used the absolute value of the measures and the longitudinal analysis used the change in function from R2 to R4 divided by the time interval between the two surveys $\left(\left(\mathrm{FVC}_{\mathrm{R} 4}-\mathrm{FVC}_{\mathrm{R} 2}\right) /\left(\right.\right.$ date $_{\mathrm{R} 4}-$ date $\left._{\mathrm{R} 2}\right)=1 /$ year $)$. Some analyses also used the per cent predicted based on Crapo et al. ${ }^{16}$

Methods by which cumulative exposure to respirable coal mine dust were estimated for the cohort have been described in detail elsewhere. ${ }^{121718}$ Briefly, exposure data collected for legal compliance purposes under the auspices of the Mine Safety and Health Administration were used. The data for the analysis included only personal samples collected on miners for the period 1970 to the end of 1987 in the 36 mines from which the R4 cohort was originally selected. Several potential biases in the data were identified and where possible, corrections were made to account for them. ${ }^{17}$ Arithmetic mean exposures were estimated within strata defined by mine, occupation, and year and for decreasingly specific stratifications: occupation/ year, mine/year (within occupation group), and year (within occupation group). To minimise the variance of means for occupation/mine/year strata with very few samples, the three way means were combined with two way (occupation/year) means in a manner that minimised the mean squared error. ${ }^{18}$ Cumulative exposure was estimated for each cohort member by matching each occupation/mine/year specific job identified in the oral work histories obtained at R4 and the estimated mean exposures. 
Table 1 Description of the study cohort by smoking state*

\begin{tabular}{|c|c|c|c|c|}
\hline & \multirow[b]{2}{*}{ Whole cohort } & \multicolumn{3}{|c|}{ Smoking state (at R4) } \\
\hline & & Current & $E x$ & Never \\
\hline $\begin{array}{l}\text { No } \\
\text { Age (y) } \\
\text { Cumulative exposure }\left(\mathrm{mg} / \mathrm{m}^{3} \text {-years) }\right. \\
\text { Pre-R2 cumulative exposure } \\
\text { Post-R2 mean exposure }\left(\mathrm{mg} / \mathrm{m}^{3}\right)\end{array}$ & $\begin{array}{l}977 \\
39 \cdot 9(6 \cdot 3) \\
15 \cdot 4(6 \cdot 2) \\
3 \cdot 8(2 \cdot 9) \\
0 \cdot 92(0 \cdot 38)\end{array}$ & $\begin{array}{l}385 \\
39 \cdot 5(6 \cdot 1) \\
15 \cdot 9(6 \cdot 2) \\
4 \cdot 0(3 \cdot 0) \\
0 \cdot 94(0 \cdot 38)\end{array}$ & $\begin{array}{l}319 \\
41 \cdot 0(6 \cdot 6) \\
15 \cdot 1(6 \cdot 1) \\
3 \cdot 8(2 \cdot 8) \\
0 \cdot 89(0 \cdot 38)\end{array}$ & $\begin{array}{l}273 \\
39 \cdot 0(6 \cdot 2) \\
15 \cdot 2(6 \cdot 4) \\
3 \cdot 5(2 \cdot 8) \\
0 \cdot 93(0 \cdot 39)\end{array}$ \\
\hline Race (\% white) & $94 \cdot 8(926)$ & $94 \cdot 8(365)$ & $95.9(306)$ & $93 \cdot 4(255)$ \\
\hline Pack-years & $12 \cdot 3(14 \cdot 1)$ & $19 \cdot 0(13 \cdot 0)$ & $14 \cdot 7(14 \cdot 8)$ & $0 \cdot 0$ \\
\hline $\begin{array}{l}\text { FVC: } \\
\text { R2 (1) } \\
\text { R2 (\% predicted) } \\
\text { R4 (1) } \\
\text { R4 (\% predicted) } \\
\text { R4-R2 (1/y) }\end{array}$ & $\begin{array}{l}5 \cdot 47(0 \cdot 78) \\
103 \cdot 7(12 \cdot 2) \\
4 \cdot 98(0 \cdot 83) \\
97 \cdot 0(13 \cdot 2) \\
-0.039(0.039)\end{array}$ & $\begin{array}{l}5 \cdot 41(0 \cdot 76) \\
102 \cdot 9(12 \cdot 0) \\
4 \cdot 89(0 \cdot 80) \\
95 \cdot 6(12 \cdot 7) \\
-0 \cdot 041(0 \cdot 036)\end{array}$ & $\begin{array}{l}5.56(0.76) \\
105 \cdot 0(12 \cdot 4) \\
5.06(0.83) \\
98.4(13 \cdot 7) \\
-0.039(0.041)\end{array}$ & $\begin{array}{l}5 \cdot 47(0 \cdot 83) \\
103 \cdot 1(12 \cdot 4) \\
5 \cdot 02(0 \cdot 86) \\
97 \cdot 2(13 \cdot 3) \\
-0.036(0 \cdot 042)\end{array}$ \\
\hline $\begin{array}{l}\mathrm{FEV}_{1}: \\
\text { R2 (1) } \\
\text { R2 (\% predicted) } \\
\text { R4 (1) } \\
\text { R4 (\% predicted) } \\
\text { R4-R2 (1/y) }\end{array}$ & $\begin{array}{l}4.33(0.67) \\
98 \cdot 3(12 \cdot 7) \\
3 \cdot 87(0 \cdot 71) \\
92 \cdot 4(14 \cdot 3) \\
-0.037(0.032)\end{array}$ & $\begin{array}{l}4 \cdot 23(0 \cdot 67) \\
96 \cdot 3(12 \cdot 7) \\
3 \cdot 70(0 \cdot 72) \\
88 \cdot 7(14 \cdot 3) \\
-0.041(0.032)\end{array}$ & $\begin{array}{l}4.39(0.67) \\
99.8(13.0) \\
3.97(0.71) \\
94.9(14.5) \\
-0.034(0.033)\end{array}$ & $\begin{array}{l}4.40(0 \cdot 65) \\
99 \cdot 4(12 \cdot 0) \\
3 \cdot 98(0 \cdot 67) \\
94.6(12 \cdot 8) \\
-0.033(0 \cdot 029)\end{array}$ \\
\hline $\begin{array}{l}\mathrm{FEV}_{1} \text { FVC: } \\
\text { R2 (\%) } \\
\text { R2 (\% predicted) } \\
\text { R4 (\%) } \\
\text { R4 (\% predicted) } \\
\text { R4-R2 (\%/y) }\end{array}$ & $\begin{array}{l}79 \cdot 3(7 \cdot 4) \\
94 \cdot 8(8 \cdot 5) \\
77 \cdot 7(7 \cdot 3) \\
95 \cdot 4(8 \cdot 8) \\
-0 \cdot 12(0 \cdot 43)\end{array}$ & $\begin{array}{l}78 \cdot 0(8 \cdot 0) \\
93 \cdot 6(8 \cdot 8) \\
75 \cdot 7(7 \cdot 8) \\
92 \cdot 9(9 \cdot 3) \\
-0 \cdot 20(0 \cdot 42)\end{array}$ & $\begin{array}{l}79 \cdot 0(8 \cdot 0) \\
95 \cdot 0(8 \cdot 6) \\
78 \cdot 4(7 \cdot 0) \\
96 \cdot 6(8 \cdot 4) \\
-0 \cdot 05(0 \cdot 43)\end{array}$ & $\begin{array}{l}81 \cdot 0(7 \cdot 0) \\
96 \cdot 5(7 \cdot 8) \\
79 \cdot 6(6 \cdot 4) \\
97 \cdot 6(7 \cdot 6) \\
-0 \cdot 09(0 \cdot 40)\end{array}$ \\
\hline
\end{tabular}

*Variables given as measured at $\mathbf{R 4}$.

Values are means (SD); pulmonary function based on Crapo et al. ${ }^{16}$

When estimates for the three way stratification exposures were unavailable, estimates based on decreasingly specific stratifications were used. Cumulative exposure to respirable coal mine dust was also partitioned for each miner into the pre-R2 and post-R2 periods. For longitudinal analyses that examined the change per year in pulmonary function between $R 2$ and $R 4$, the post-R2 cumulative exposure was standardised to the time between surveys and presented as the average exposure over the interval in $\mathrm{mg} / \mathrm{m}^{3}$.

Multiple regression analyses were conducted to simultaneously control for age, height, cigarette smoking (current, ex, never), pack-years of cigarette smoking, race/ethnicity (White, Black, Hispanic), mining state at R4 (current, ex) and years worked in non-mining dusty occupations. Age, height, pack-years, non-mining dust exposure and cumulative exposure to respirable coal mine dust were entered into the models as continuous variables; current and ex-smoker, mining state, and race/ethnicity were represented by dummy variables. For the longitudinal analysis of changes from R2 to R4, variables such as age and smoking history were obtained from the R4 results. For cross sectional analysis of $\mathrm{R} 2$, data from that survey were used. Cumulative exposure up to $\mathrm{R} 2$ or $\mathrm{R} 4$ were always included in the respective cross sectional analyses. For the longitudinal analyses, pre-R2 cumulative exposure and post-R2 average exposure were used. All variables other than exposure to dust were selected first by a simple forward stepwise procedure ( $\mathrm{p}$ for inclusion $<0 \cdot 2$ ). All selected variables with $\mathrm{p}$ between $0 \cdot 1$ and $0 \cdot 2$ were then evaluated to determine their effect on the cumulative exposure coefficient. If removal of the variable resulted in a change in the coefficient for cumulative exposure greater than $10 \%$, the covariate remained in the model. A previous cross sectional analysis of R4 found that the use of the log of cumulative exposure and interactions between age, smoking state, and exposure improved the fit of the model. ${ }^{13}$ No such improvement was found for the $\mathrm{R} 2$ or change from R2 to R4 analyses presented here, so only the simple linear models are presented to allow comparability across time frames of analysis. After we identified the model, further improvements were tested through the addition of age ${ }^{2}$ and interaction terms between exposure and age and exposure and smoking variables. The fit for each primary model was evaluated by examining residual plots for outliers and non-random patterns. No evidence of systematic poor fit was found.

\section{Results}

Of the 1185 miners meeting the cohort definition for the earlier analysis, ${ }^{13} 977$ had pulmonary function tests at R2. Table 1 gives the characteristics and pulmonary function results for this population, stratified by $\mathrm{R} 4$ smoking state. The average age at R4 was about 40 and cumulative exposure was 
Table 2 Linear regression models for change per year of pulmonary function varables between $R 2$ and $R 4(n=977)$ *

\begin{tabular}{|c|c|c|c|}
\hline & $F V C$ & $F E V_{1}$ & $F E V_{1} / F V C \%$ \\
\hline $\mathrm{r}^{2}$ Constant & $\begin{array}{l}0.109 \\
-0.2368 \\
0.0452 \\
(<0.001)\end{array}$ & $\begin{array}{l}0.065 \\
0.0858 \\
0.0377 \\
(0.023)\end{array}$ & $\begin{array}{l}0.044 \\
-1.8863 \\
0.5079 \\
(<0.001)\end{array}$ \\
\hline Age (y) & $\begin{array}{l}-0.0116 \\
0.0022 \\
(<0.001)\end{array}$ & $\begin{array}{l}-0.0049 \\
0.0018 \\
(0.007)\end{array}$ & $\begin{array}{l}0.0823 \\
0.0242 \\
(<0.001)\end{array}$ \\
\hline $\mathrm{Age}^{2}$ & $\begin{array}{l}0.00011 \\
0.00003 \\
(<0.001)\end{array}$ & $\begin{array}{l}0.00004 \\
0.00002 \\
(0.032)\end{array}$ & $\begin{array}{l}-0.00092 \\
-0.00028 \\
(0.001)\end{array}$ \\
\hline $\begin{array}{l}\text { Current smoker } \\
(0=\text { no, } 1=\text { yes })\end{array}$ & $\begin{array}{l}-0.0044 \\
0.0024 \\
(0.073)\end{array}$ & $\begin{array}{l}-0.0087 \\
0.0020 \\
(<0.001)\end{array}$ & $\begin{array}{l}-0.1305 \\
0.0274 \\
(<0.001)\end{array}$ \\
\hline $\begin{array}{l}\text { Current miner } \\
(0=\text { no, } 1=\text { yes })\end{array}$ & & $\begin{array}{l}-0.0033 \\
0.0021 \\
(0.107)\end{array}$ & \\
\hline $\begin{array}{l}\text { Black } \\
(0=\text { no, } 1=\text { yes })\end{array}$ & & & $\begin{array}{l}0.1554 \\
0.0678 \\
(0.022)\end{array}$ \\
\hline $\begin{array}{l}\text { Pre-R2 } \\
\quad \text { Cumulative }\end{array}$ & & & \\
\hline exposure ${ }^{\dagger}$ & $\begin{array}{l}0.0012 \\
0.0004 \\
(0.006)\end{array}$ & $\begin{array}{l}0.0007 \\
0.0004 \\
(0.066)\end{array}$ & $\begin{array}{l}-0.0059 \\
0.0049 \\
(0.232)\end{array}$ \\
\hline $\begin{array}{l}\text { Post-R2 mean } \\
\text { exposure }\end{array}$ & $\begin{array}{l}-0.0018 \\
0.0032 \\
(>0.2)\end{array}$ & $\begin{array}{l}0.0028 \\
0.0028 \\
(>0 \cdot 2)\end{array}$ & $\begin{array}{l}0.0472 \\
0.0361 \\
(0.0191)\end{array}$ \\
\hline
\end{tabular}

*Calculations from pulmonary function values in 1 per year (FVC $\left.\mathrm{FEV}_{1}\right)$ and $\%$ per year $\left(\mathrm{FEV}_{1} / \mathrm{FVC} \%\right)$

${ }^{+}$Cumulative exposure (mg/m $\mathrm{m}^{3}$-years) up to $\mathrm{R} 2$ (pre-R2) and mean exposure $\left(\mathrm{mg} / \mathrm{m}^{3}\right)$ between $\mathrm{R} 2$ and $\mathrm{R} 4$ (post-R2).

Results are coefficient, standard error, ( $p$ value).

about $15 \mathrm{mg} / \mathrm{m}^{3}$-years. More than one third of the group were current smokers at R4. The $\mathrm{FEV}_{1}$ and FVC as a per cent of predicted declined between R2 and R4. The average changes in FVC and FEV over the interval were 39 and $37 \mathrm{ml}$ per year respectively.

Linear regression models were developed for the change per year in each of the pulmonary function test measures (table 2). Inclusion of a quadratic age term to the models improved the model fit but none of the interactions considered were significant $(p>0.05)$. No statistically significant associations were found between post-R2 average exposure and pulmonary function changes. There was a small but statistically significant increase in FVC and FEV with higher pre-R2 cumulative exposures. The low $\mathbf{r}^{2}$ values for these models are similar to other longitudinal pulmonary function studies of coal miners with two time points..$^{10}$

Because these findings on exposure to dust and ventilatory function seem to contradict those from an earlier cross sectional study of R4 miners, ${ }^{13}$ further analyses were undertaken. Firstly, to confirm that the previously detected trend of decline in ventilatory function with increasing dust exposure was still evident in the subset of R4 data examined here, a cross sectional analysis of the R4 pulmonary
Table 3 Linear regression models for pulmonary function outcomes at $R 4(n=977) \star$

\begin{tabular}{|c|c|c|c|}
\hline & $F V C$ & $F E V_{I}$ & $F E V, / F V C \%$ \\
\hline $\begin{array}{l}r^{2} \\
\text { constant }\end{array}$ & $\begin{array}{l}0.407 \\
-5.4734 \\
0.6387 \\
(<0.001)\end{array}$ & $\begin{array}{l}0.439 \\
-3.0636 \\
0.5370 \\
(<0.001)\end{array}$ & $\begin{array}{l}0 \cdot 157 \\
92 \cdot 819 \\
1 \cdot 5328 \\
(<0.001)\end{array}$ \\
\hline Age (y) & $\begin{array}{l}-0.0379 \\
0.0033 \\
(<0.001)\end{array}$ & $\begin{array}{l}-0.0423 \\
0.0030 \\
(<0.001)\end{array}$ & $\begin{array}{l}-0.3120 \\
0.0370 \\
(<0.001)\end{array}$ \\
\hline Height $(\mathrm{cm})$ & $\begin{array}{l}0.0682 \\
0.0034 \\
(<0.001)\end{array}$ & $\begin{array}{l}0.0497 \\
0.0029 \\
(<0.001)\end{array}$ & \\
\hline $\begin{array}{l}\text { Current smoker } \\
(0=\text { no, } 1=\text { yes })\end{array}$ & $\begin{array}{l}-0.1138 \\
0.0422 \\
(0.007)\end{array}$ & $\begin{array}{l}-0.1182 \\
0.0518 \\
(0.023)\end{array}$ & $\begin{array}{l}-2.7668 \\
0.4895 \\
(<0.001)\end{array}$ \\
\hline $\begin{array}{l}\text { Ex-smoker } \\
(0=\text { no, } 1=\text { yes })\end{array}$ & & $\begin{array}{l}0.1167 \\
0.0493 \\
(0.018)\end{array}$ & \\
\hline Pack-years & & $\begin{array}{l}-0.0056 \\
0.0016 \\
(<0.001)\end{array}$ & $\begin{array}{l}-0.0499 \\
0.0180 \\
(0.006)\end{array}$ \\
\hline $\begin{array}{l}\text { Black } \\
(0=\text { no, } 1=\text { yes })\end{array}$ & $\begin{array}{l}-0.8851 \\
0.1040 \\
(<0.001)\end{array}$ & $\begin{array}{l}-0.5392 \\
0.0872 \\
(<0.001)\end{array}$ & $\begin{array}{l}3.2682 \\
1.0950 \\
(0.003)\end{array}$ \\
\hline $\begin{array}{l}\text { Hispanic } \\
(0=\text { no, } 1=\text { yes })\end{array}$ & & & $\begin{array}{l}4 \cdot 1205 \\
2 \cdot 0604 \\
(0 \cdot 046)\end{array}$ \\
\hline $\begin{array}{l}\text { Cumulative } \\
\text { exposure }\end{array}$ & $\begin{array}{l}-0.0020 \\
0.0033 \\
(>0.2)\end{array}$ & $\begin{array}{l}-0.0059 \\
0.0028 \\
(0.033)\end{array}$ & $\begin{array}{l}-0.0775 \\
0.0350 \\
(0.027)\end{array}$ \\
\hline
\end{tabular}

*Calculations from pulmonary function values in l(FVC, FEVM) and $\%\left(\mathrm{FEV}_{1} / \mathrm{FVC}_{\mathrm{P}}\right)$

†Cumulative exposure ( $\mathrm{mg} / \mathrm{m}^{3}$-years).

Results are coefficient, standard error, ( $p$ value).

Table 4 Linear regression models for pulmonary function variable at $R 2$

\begin{tabular}{llll}
\hline & $F V C$ & $F E V_{t}$ & $F E V_{I} / F V C \%$ \\
\hline $\mathrm{r}^{2}$ & 0.379 & 0.393 & 0.140 \\
Constant & -7.8990 & -4.9735 & 101.44 \\
& 0.7102 & 0.6018 & 6.559 \\
Age (y) & $(<0.001)$ & $(<0.001)$ & $(<0.001)$ \\
& 0.0794 & 0.0445 & -0.3020 \\
& 0.0260 & 0.0220 & 0.0402 \\
Age $^{2}$ & $(0.002)$ & $(0.044)$ & $(<0.001)$ \\
& -0.0015 & -0.0012 & \\
& 0.0004 & 0.0004 & \\
Height (cm) & $(<0.001)$ & $(0.001)$ & \\
& 0.0708 & 0.0517 & -0.0719 \\
& 0.0033 & 0.0028 & 0.0362 \\
Ex-smoker & $(<0.001)$ & $(<0.001)$ & $(0.047)$ \\
(0= no, 1 = yes) & & 0.0910 & \\
Pack-years & & 0.0447 & \\
& & $(0.042)$ & -0.1452 \\
Black & & 0.0094 & 0.0299 \\
(0= no, 1 = yes) & 0.1003 & 0.0023 & $(<0.001)$ \\
Cumulative & $(<0.001)$ & $(<0.001)$ & \\
exposure & & & \\
Pre-R2 $\dagger$ & -0.0304 & -0.0275 & -0.0816 \\
& 0.0071 & 0.0060 & 0.0766 \\
& $(<0.001)$ & $(<0.001)$ & $(>0.2)$ \\
\hline
\end{tabular}

*Calculations from pulmonary function values in $1\left(\mathrm{FVC}, \mathrm{FEV}_{1}\right)$ and $\%\left(\mathrm{FEV}_{1} / \mathrm{FVC} \%\right)$.

tCumulative exposure ( $\mathrm{mg} / \mathrm{m}^{3}$-years) up to $\mathrm{R} 2$.

Results are coefficient, standard error, ( $p$ value). 
Table 5 Linear regression models for FVC and FEV, at $R 2$ by age category *

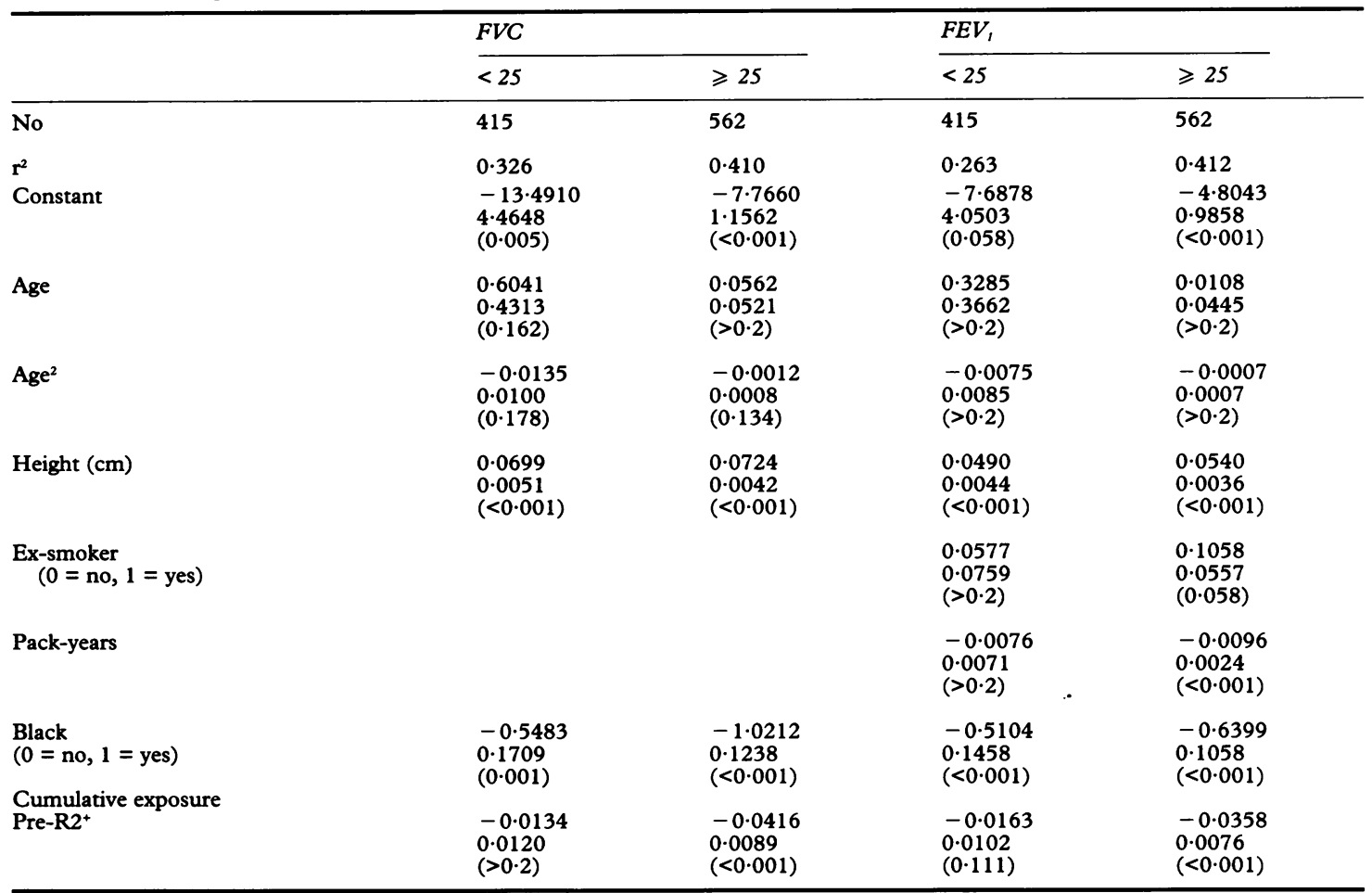

* Calculations from pulmonary function values in 1 (FVC, $\mathrm{FEV}_{1}$ ).

t Cumulative exposure ( $\mathrm{mg} / \mathrm{m}^{3}$-years) up to $\mathrm{R} 2$.

Results are coefficient, standard error, $p$ value.

function data was repeated with cumulative exposure before R4. The results (table 3 ) were similar to those found previously. ${ }^{13}$ The $\mathrm{FEV}_{1}$ and $\mathrm{FEV}_{1} /$ FVC were associated with cumulative exposure and the estimated effect of exposure on $\mathrm{FEV}_{1}$ was -5.9 $\mathrm{ml}$ per $\mathrm{mg} / \mathrm{m}^{3}$-years.

Table 6 Regression coefficients for cumulative exposure (preR2) from previously developed models (table 4) for pulmonary function variables stratified by $R 2$ smoking state*

\begin{tabular}{llll}
\hline Smoking State & $F V C$ & $F E V_{1}$ & $F E V, / F V C \%$ \\
\hline Current $(\mathrm{n}=557)$ & -0.0254 & -0.0237 & -0.1089 \\
& 0.0089 & 0.0078 & 0.0990 \\
& $(0.004)$ & $(0.002)$ & $(>0.2)$ \\
Ex $(\mathrm{n}=169)$ & -0.0449 & -0.0524 & -0.2476 \\
& 0.0186 & 0.0160 & 0.1999 \\
& $(0.017)$ & $(0.001)$ & $(>0.2)$ \\
Never (n=251) & -0.0335 & -0.0179 & 0.0888 \\
& 0.0148 & 0.0117 & 0.1525 \\
& $(0.025)$ & $(0.128)$ & $(>0.2)$ \\
\hline
\end{tabular}

Calculations from pulmonary function values in 1 (FVC, FEV ${ }_{1}$ ) and FEV1/FVC\%). Results are coefficient, standard error, (p value).

Each coefficient was derived from a separate multivariate linear regression model. Covariates included (not shown) age, age ${ }^{2}$, height, race, and smoking history as in table 4.
As the previously noted cross sectional relations between ventilatory function and exposure to dust were not clearly echoed in the longitudinal analysis, it seems that much of the dust related decline in ventilatory function evident at R4 must have occurred before the start of the longitudinal follow up period-that is, before R2. Hence, further cross sectional analyses were undertaken modelling R2 ventilatory function with cumulative dust exposure before R2. These results (table 4) indicated a strong association of cumulative exposure with reduced pulmonary function (FVC and $F_{E V}$ were some $30 \mathrm{ml}$ lower for each additional $\mathrm{mg} / \mathrm{m}^{3}$-years worked). This association was found over an average exposure time of about 2.5 years, with a maximum mining experience of about five years.

Because pulmonary function is expected to peak at about age 25 before beginning its age related decline, separate regressions were run for miners less than age 25 and greater than or equal to 25 years at R2 (table 5). Miners less than 25 years old did not have statistically significant declines in FVC or $\mathrm{FEV}_{1}$ associated with exposure, although the point estimates of -13.4 and $-16.3 \mathrm{ml}$ per $\mathrm{mg} / \mathrm{m}^{3}$-years are substantial. Miners older than 25 
years had striking dust related decrements of the order of $-40 \mathrm{ml}$ per $\mathrm{mg} / \mathrm{m}^{3}$-years.

To further examine the effect of smoking at R2, the regressions presented in table 4 were rerun stratified by R2 smoking state (table 6). Exposure related decrements were present for both FVC and $\mathrm{FEV}_{1}$ in all smoking categories. The largest coefficients were ex-smokers. Never smokers had a statistically significant loss of FVC in relation to dust exposure and the exposure-related loss of $\mathrm{FEV}_{1}$ for never smokers was somewhat smaller (about $16 \mathrm{ml}$ per $\mathrm{mg} / \mathrm{m}^{3}$-year) than for the other two smoking groups and was not statistically significant $(\mathrm{p}>0 \cdot 1)$.

\section{Discussion}

This study suggests that coal miners beginning their mining tenure at the same time that the federal government instituted comprehensive exposure regulations have experienced exposure related losses of lung function but that the losses were not linearly related to exposure over time. During the first few years of mining (less than five), the miners seem to have had a rapid initial loss of lung function associated with their cumulative exposure to respirable coal mine dust. There was a comparable effect on both the FVC and $\mathrm{FEV}_{1}$ of about $30 \mathrm{ml}$ for each $\mathrm{mg} / \mathrm{m}^{3}$-year of exposure and the effect was more pronounced $\left(-40 \mathrm{ml}\right.$ per $\mathrm{mg} / \mathrm{m}^{3}$-year) in miners over the age of 25 at R2. Over the next 10 to 14 years, although the mean $\mathrm{FEV}_{1}$ and $\mathrm{FVC}$ as a per cent of predicted declined (table 1), no additional loss associated with continued exposure was detected.

The models presented in this analysis were simple linear regressions. In a previous cross sectional analysis at R4, stronger associations were found from the $\log$ of cumulative exposure and interactions between smoking state, age, and log cumulative exposure. ${ }^{13}$ In the analysis of $\mathrm{R} 2$ or the change from R2 to R4, no improvement was found by substituting the log of exposure. To keep the analyses consistent and more easily interpretable, only the simple linear models were presented for the R4 cross sectional analysis. The stronger association of pulmonary function with the $\log$ of cumulative exposure at R4 may, in fact, be related to the large effect of early exposures in this analysis.

The changes in pulmonary function (especially FVC) between R2 and R4 were associated with the earlier exposures (the pre- $\mathrm{R} 2$ cumulative exposure), but in the opposite direction from that expected. It seems plausible that this result stems from a recovery after the initial exposure related decrements. That is, miners with heavy initial dust exposure and pulmonary function decrements may have a subsequent recovery or slowing of loss and seem to have a positive pre- $\mathrm{R} 2$ exposure to post- $\mathrm{R} 2$ change in pulmonary function relations.

The apparent lack of association between the exposure between R2 and R4 and decrements in FVC and $F V_{1}$ in the longitudinal analysis (table 2) should be considered carefully. In a study of 418 non-occupationally exposed non-smoking adults followed up in up to seven surveys over 11 years, Burrows, et $a l^{19}$ were able to generate estimates of decline in $\mathrm{FEV}_{1}$ with time. They found that the mean $F_{E V}$ in different surveys deviated from the predicted values by as much as $\pm 30 \mathrm{ml}$. Such survey effects were not explained by any changes in personnel, equipment, or methodology. Furthermore, Berry ${ }^{20}$ used an estimate of between occasion (between survey) standard deviation in $\mathrm{FEV}_{1}$ of 120 $\mathrm{ml} /$ year derived from five longitudinal studies of working populations to calculate the standard deviation of estimates of annual declines. His results indicate that in a study comparable with this one (two measurements 10 years apart), a standard deviation of annual decline of $43 \mathrm{ml}$ per year would be expected. The standard deviation of annual decline was $32 \mathrm{ml}$ per year in our current study. In view of this, the power to detect an exposure related effect on FEV 1 less than 2 or $3 \mathrm{ml}$ per $\mathrm{mg} / \mathrm{m}^{3}$ is probably limited in the current longitudinal analysis.

Selection effects might be invoked to provide an explanation for the large exposure-response relation at R2. If miners with lower initial pulmonary function were selected into jobs with high exposures, a falsely positive exposure-response analysis at R2 with no subsequent change might be found. Such a selection process, however, seems implausible. The apparent lack of any exposure-response during the R2-R4 interval could conceivably be explained by selection effects if ill members of the cohort were less likely to participate at R4. Although such an effect cannot be ruled out entirely, R4 participants and non-participants were found to be similar at R2 in a previous analysis. ${ }^{13}$ In that analysis, the $\mathrm{R} 4$ participants and non-participants did not differ significantly in age (27.6 and 26.4$)$, pack-years $(6.2$ and $6.0)$, per cent predicted FVC (103.8 and 103.0), $\mathrm{FEV}_{1}$ (98.6 and 98.9), and $\mathrm{FEV}_{1} / \mathrm{FVC}(95.0$ and 95.9).

Selection bias could account for the minimal effect of dust from R2 to R4 if miners who were more susceptible to the dust were less likely to participate in both R2 and R4. This is unlikely to be operative given that the effect in the pre-R2 period was so pronounced, suggesting that susceptible miners were included in the group.

One possible explanation for the difference in dust effect at R2 and from R2 to R4 is raised by the finding of Mannino et al, that miners with airways hyper-responsiveness were more likely to work in 
low exposure jobs. ${ }^{21}$ If the young cohort in the current analysis at $\mathbf{R} 2$ included a sub-group of miners with hyper-reactive airways, who later migrated to lower exposure jobs, this could result in high initial dust-related effects and lower effects subsequently. Given the fact, that R2 participants also participating in R4 were not substantially different from eligible non-participants in R4, however, selective migration to low exposure jobs by miners with airways hyper-reactivity seems unlikely to solely explain the differences seen between R2 and R4.

It is also conceivable that differential errors in measurements explained the results. For instance, if the pre- $R 2$ exposure estimates were highly accurate and precise, and the post $\mathrm{R} 2$ estimates contained substantial random misclassification resulting in a bias toward the null hypothesis, then the exposure-response analysis might behave as found. This phenomenon is unlikely, however, because the dust estimates were obtained in the same manner in both periods. In fact, dust concentration measurements in the first few years of the programme are somewhat less reliable than in later years ${ }^{22}$ and the occupational histories recalled for the more distant time periods are more likely to be misclassified. ${ }^{23}$ Thus greater misclassification may exist in the exposure estimates for the pre-R2 years.

Given that exposure levels were higher (1.5 to two times) during the pre-R2 period than during the subsequent years, ${ }^{18}$ another possible explanation of the rapid initial loss of function is that intensity of exposure to dust is responsible for the effects. We might hypothesise that a threshold value exists, below which dust exposure has no effect on the airways and above which, a strong dose-dependent effect occurs. An analysis of the exposure-response relation at $\mathrm{R} 4$ on miners who had never worked in jobs with exposures exceeding $2.0 \mathrm{mg} / \mathrm{m}^{3}(\mathrm{n}=344)$ indicated that a significant exposure-response relation was present even for these miners with the lower maximum exposures (coefficient for cumulative exposure: -0.0213 $\mathrm{FEV}_{1}$ per $\mathrm{mg} / \mathrm{m}^{3}$-years, $\mathrm{p}=0.002$ ). A similar analysis with a threshold cutoff of $1.5 \mathrm{mg} / \mathrm{m}^{3}$ was not informative because so few miners had worked in jobs with these lower exposures.

The per cent predicted FVC and $\mathrm{FEV}_{1}$ were lower in R4 than in R2 in all smoking categories (table 1) although no exposure-related decrements for this time were found. One plausible interpretation of this finding is that exposure did affect pulmonary function and that random variability in the exposure and pulmonary function data was too great to permit its detection. It is also possible that ethnic, climatic, or other unspecified factors led to more rapid age related declines than expected on the basis of the prediction formulas of Crapo et al ${ }^{16}$

The differences in response to dust in miners younger and older than age 25 (table 5) are unexplained. Although the cumulative exposures of the two groups were different (mean 3.1 and 4.3 $\mathrm{mg} / \mathrm{m}^{3}$-years respectively) the difference was not sufficiently large to suggest a threshold phenomenon to explain the result. Further stratification by age into four groups did not change the pattern substantially (for FEV 1 the coefficients for cumulative exposure were $-0.021,-0.011,-0.040$ and $-0.026 \mathrm{ml}$ per $\mathrm{mg} / \mathrm{m}^{3}$-years, for age groups $<23$, $23-25,25-30$, and $\geqslant 30$ years respectively). Given these findings, physiological differences between younger and older miners may account for the disparate responses to exposure to dust.

Several studies of coal miners have reported either obstructive lung disease occurring as a chronic process requiring the accumulated insult of dust exposure over many years, ${ }^{18}$ or restrictive lung disease among the subset of workers who evidence large opacities (progressive massive fibrosis) on chest $x$ ray films. ${ }^{24}$ Also, there is increasing evidence of a restrictive process among coal miners even in the absence of progressive massive fibrosis. ${ }^{46}$

For instance, Soutar and Hurley found parallel

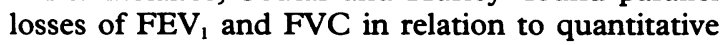
estimates of lifetime dust exposure in a study of 4059 British miners and ex-miners with no progressive massive fibrosis. The findings of this study, however, may not be comparable with the current analysis as cumulative exposures were significantly higher and there is little tendency in the current data toward a progression of the losses in FVC as would be expected in an ongoing fibrotic process. The long term losses found among the British miners may represent a combination of a classic restrictive (for example, loss due to irreversible interstitial fibrosis) and obstructive (airways narrowing and emphysematous) processes. By contrast, the rapid initial loss of function over a short period with relatively low dust concentrations and the parallel loss of FVC and FEV 1 we found, are unlikely to represent either an interstitial fibrotic process, or the more gradual obstructive changes usually seen in dust induced chronic obstructive disease.

It is also important to note that the effect estimates from the cross sectional British studies are considerably lower than those obtained cross sectionally here, even at R4. Estimates from British studies range from about 1.0 to $1.6 \mathrm{ml} \mathrm{FEV}_{1}$ per $\mathrm{mg} / \mathrm{m}^{3}$-year ${ }^{25}$ compared with the $5.9 \mathrm{ml}$ at $\mathrm{R} 4$ or $27.5 \mathrm{ml} \mathrm{decrement}$ per $\mathrm{mg} / \mathrm{m}^{3}$-year in our current study. Possible reasons for the differences are discussed in detail in an earlier paper, ${ }^{13}$ and include the differences in the cohort's ages (the British cohort was older), work histories (British workers had worked substantially longer in significantly higher dust concentrations), misestimation of either the British or American dust concentrations, 
chance (the $95 \%$ confidence intervals at $\mathrm{R} 4$ include the British effect estimates), and finally, nonlinearities in the effect of dust on the airways. Given the results in this paper, the non-linearity of effect may be an important reason for the apparent discrepancies.

Only one other study of lung function in miners during their initial years of mining has been reported. Hodous and Hankinson ${ }^{26}$ studied a group of 65 new miners with measures of pulmonary function every six months for two years and once more five years later. The average age at the first examination was $29 \mathrm{y}$. During the first two years, the miners lost 134 and $200 \mathrm{ml}$ of FVC and $\mathrm{FEV}_{1}$ respectively, or an average loss of 67 and $100 \mathrm{ml}$ per year. During the next five years, they lost an average of only a further $72 \mathrm{ml} \mathrm{FEV}$, a rate of loss of $14.4 \mathrm{ml}$ per year. Over the same five year period, the miners gained $107 \mathrm{ml}$ of FVC for an average gain of $21.4 \mathrm{ml}$ per year. No exposure measurements were made on these miners and no control group followed up for the same period. Although not conclusive, the results suggest that miners had an accelerated loss of function over the first two years of mining exposure with a substantial levelling off of decline in $\mathrm{FEV}_{1}$ and a reversal of the initial losses reflected in the FVC. Given the surprising results obtained, the authors discounted their findings as a result of random variability. In view of the striking similarity of their results with the current analysis, Hodous and Hankinson's results deserve more consideration.

The apparently rapid onset of a dust-related effect that later moderates may be consistent with an inflammatory response to exposure to coal dust. A restrictive pattern of pulmonary function could be seen with an inflammatory process of the small airways. Dust depositing in the alveoli may be cleared by macrophages to the terminal bronchioles and, along with dust depositing there, elicit an inflammatory response ${ }^{27}$ that may be reversible. ${ }^{28}$ Although an inflammatory response of the small airways is usually associated with obstructive pulmonary function, ${ }^{29}$ it may also be consistent with restrictive changes. For instance, Churg et al $^{30}$ have described a lesion of the small airways that resulted from exposure to mineral dust. Although the report of Chung et al considered primarily obstructive changes, the effect on the FVC was similar to the effect on the $\mathrm{FEV}_{1}$ with little change in the $\mathrm{FEV}_{1}$ to FVC ratio, suggesting a restrictive effect.

The relation of any such hypothesised sub-acute inflammatory changes to chronic lung disease in miners is unclear. It is possible that the initial postulated inflammatory response may begin the process of emphysematous changes associated with chronic obstruction in miners, ${ }^{27}$ or the beginning of the formation of coal macules and fibrosis of the small airways associated with either $x$ ray film changes or the restrictive pattern found in some long term miners without progressive massive fibrosis.

In summary, exposures to respirable coal mine dust at concentrations present in United States mines since 1970 seem to have a substantial effect on pulmonary function, as reflected in a parallel exposure related loss of $\mathrm{FEV}_{1}$ and FVC over the first few years of exposure. Although the miners continue to lose function over subsequent years, as expressed as a per cent predicted, the loss was apparently not related to exposure. It seems that the subsequent loss of pulmonary function is less rapid. Nevertheless, over the period covered in this study (18 years), the loss of $\mathrm{FEV}_{1}$ in relation to exposure to dust persists. Investigation of the significance of the initial reaction to exposure to coal mine dust and estimation of the effect of continued low level exposure on morbidity and mortality will require further follow up.

We thank John Hankinson for assistance in preparation and interpretation of the spirometry data used for these analyses. Support for this study was received from grant $\mathrm{RO}-3-\mathrm{OH} 02627$ from the National Institute for Occupational Safety and Health of the Centers for Disease Control.

1 Rogan JM, Attfield MD, Jacobsen M, Rae S, Walker DD, Walton WH. Role of dust in the working environment in development of chronic bronchitis in British coal miners. $\mathrm{Br}$ f Ind Med 1973;30:217-26.

2 Morgan WKC, Handelsman L, Kibelstis J, Lapp NL, Reger $R$. Ventilatory capacity and lung volumes of US coal miners. Arch Environ Health 1974;28:182-9.

3 Hankinson JL, Reger RB, Fairman RP, Lapp NL, Morgan WKC. Factors influencing expiratory flow rates in coal miners. In: inhaled particles IV, WH Walton ed. Oxford: Pergamon Press, 1977;737-55.

4 Soutar CA, Hurley JF. Relation between dust exposure and lung function in miners and ex-miners. Br $\mathcal{F}$ Ind Med 1986; 43:307-20.

5 Marine WM, Gurr D, Jacobsen M. Clinically important respiratory effects of dust exposure and smoking in British coal miners. Am Rev Respir Dis 1988;137:106-12.

6 Attfield MD, Hodous TK. Pulmonary function of US coal miners related to dust exposure estimates. Am Rev Respir Dis 1993 (in press).

7 Rae S, Walker DD, Attfield MD. Chronic bronchitis and dust exposure in British coalminers. In: Walton WH, ed. Inhaled particles III. Old Woking, Surrey: Unwin Bros 1971; 873-81.

8 Kibelstis JA, Morgan EJ, Reger R, Lapp NL, Seaton A, Morgan WKC. Prevalence of bronchitis and airway obstruction in American bituminous coal miners. Am Rev Respir Dis 1973;108:886-93.

9 Love RG, Miller BG. Longitudinal study of lung function in coal-miners. Thorax 1982;37:193-7.

10 Attfield MD. Longitudinal decline in FEV1 in United States coalminers. Thorax 1985;40:132-7.

11 US Congress. Public Law 91-173: Federal Coal Mine Health and Safety Act of 1969. US Statutes at Large 1969;83: 742-804.

12 Seixas, NS. Dust exposure and respiratory disease in United States coal miners (dissertation). Ann Arbor, MI: Department of Environmental and Industrial Health, University of Michigan School of Public Health 1990. 
13 Seixas NS, Robins TG, Attfield MD, Moulton LH. Exposureresponse relationships for coal mine dust and obstructive lung disease following enactment of the Federal Coal Mine Health and Safety Act of 1969. Am F Ind Med 1991;21: 715-34.

14 American Thoracic Society. Standardization of spirometry. Am Rev Respir Dis 1979;119:831-8.

15 Ferris BG, Speizer FE, Bishop Y, Prang G, Weener J. Spirometry for an epidemiologic study: deriving optimum summary statistics for each subject. Bulletin de Physiopathologie Respiratoire 1978;14:146-66.

16 Crapo RO, Morris AH, Gardner RM. Reference spirometric values for spirometry using techniques and equipment that meets ATS recommendations. Am Rev Respir Dis 1981; 123:659-64.

17 Seixas NS, Robins TG, Rice CH, Moulton LH. Assessment of potential biases in the application of MSHA respirable mine dust data to an epidemiologic study. Am Ind Hyg Assoc $\mathcal{F}$ 1990;51:534-40.

18 Seixas NS, Moulton LH, Robins TG, Rice CH, Attfield MD, Zellers ET. Estimation of cumulative exposures for the National Study of Coal Workers' Pneumoconiosis. Applied Occupational and Environmental Hygiene 1993 (in press).

19 Burrows B, Lebowitz MD, Camilli AE, Knudson RJ. Longitudinal changes in forced expiratory volume in one second in adults. Am Rev Respir Dis 1985;133:974-80.

20 Berry G. Longitudinal observations. Their usefulness and limitations with special reference to the forced expiratory volume. Bulletin de Physio-pathologie-Respiratoire 1974;10: 643-55.

21 Mannino D, Daniloff E, Peck A, Petsonk E. Do miners select jobs based on airway responsiveness? (abstract). Am Rev Respir Dis 1991;143:A246.

22 National Bureau of Standards. An evaluation of the accuracy of the coal mine dust sampling program administered by the Department of the Interior. Washington, DC: National Bureau of Standards, 1975.

23 Rosenberg CR, Mulvihill MN, Fischbein A, Blum S. An analysis of the validity of self reported occupational histories using a cohort of workers exposed to PCBs. Br $\mathcal{F}$ Ind Med 1987;44:702-10.

24 Morgan WKC, Lapp NL. Respiratory disease in coal miners. Am Rev Respir Dis 1976;113:531-59.

25 Soutar CA. Occupational bronchitis. In: Harrington M, ed. Recent advances in occupational health 3. London: Churchill Livingstone, 1987;285-302.

26 Hodous TK, Hankinson JL. Prospective spirometric study of new coal miners. In Proceedings of the international symposium on pneumoconioses, 1988, Shenyang, PRC Institute of Occupational Medicine, Chinese Academy of Preventive Medicine, Beijing, PRC, 1990.

27 Vincent JH, Donaldson K. A dosimetric approach for relating the biological response of the lung to the accumulation of inhaled mineral dust. Br f Ind Med 1990;47:302-7.

28 Brown GM, Donaldson $\mathrm{K}$. Inflammatory responses in lungs of rats inhaling coalmine dust: enhanced proteolysis of fibronectin by bronchoalveolar leukocytes. $\mathrm{Br} F$ Ind $\mathrm{Med}$ 1989;66:866-72.

29 Thurlbeck WM. Chronic airlow obstruction: correlation of structure and function. In: Petty TL ed. Chronic obstructive pulmonary disease. New York: Marcel Dekker, 1985; 129-204.

30 Churg A, Wright JL, Wiggs B, Pare PD, Lazar N. Small airways disease and mineral dust exposure. Prevalence, structure and function. Am Rev Respir Dis 1985;131:139-43.

Accepted 4 January 1993

\section{Destruction of manuscripts}

From 1 July 1985 articles submitted for publication will not be returned. Authors whose papers are rejected will be advised of the decision and the manuscripts will be kept under security for three months to deal with any inquiries and then destroyed. 